\title{
Development, Implementation and Evaluation of a Peer Review of Teaching (PRoT) Initiative in Nursing Education
}

\author{
Diana Mager \\ Fairfield University, dmager@fairfield.edu \\ Meredith Wallace Kazer \\ Fairfield University, mkazer@fairfield.edu \\ Jaclyn Conelius

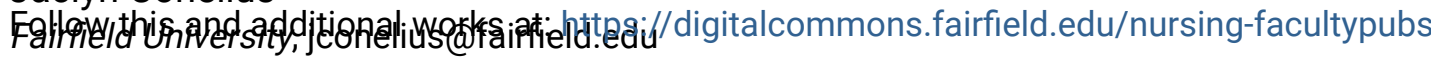 \\ Copyright 2014 Walter de Gruyter GmbH \\ thyce M. She the \\ FairfieldUniversity, jshea@fairfield.edu \\ ijnes-2013-0019/ijnes-2013-0019.xml
}

Aptifived-1penth permission from the copyright holder.

Fairfield University, dlippman@fairfield.edu

\section{Peer Reviewed}

See next page for additional authors

\section{Repository Citation}

Mager, Diana; Kazer, Meredith Wallace; Conelius, Jaclyn; Shea, Joyce M.; Lippman, Doris T.; Torosyan, Roben; and Nantz, Kathryn, "Development, Implementation and Evaluation of a Peer Review of Teaching (PRoT) Initiative in Nursing Education" (2014). Nursing and Health Studies Faculty Publications. 58. https://digitalcommons.fairfield.edu/nursing-facultypubs/58

\section{Published Citation}

Mager, Diana R., Meredith W. Kazer, Jaclyn Conelius, Joyce Shea, Doris T. Lippman, Roben Torosyan, and Kathryn Nantz. "Development, implementation and evaluation of a peer review of teaching (PRoT) initiative in nursing education." International journal of nursing education scholarship 11, no. 1 (2014): 113-120. DOI: 10.1515/ ijnes-2013-0019

This item has been accepted for inclusion in DigitalCommons@Fairfield by an authorized administrator of DigitalCommons@Fairfield. It is brought to you by DigitalCommons@Fairfield with permission from the rightsholder(s) and is protected by copyright and/or related rights. You are free to use this item in any way that is permitted by the copyright and related rights legislation that applies to your use. For other uses, you need to obtain permission from the rights-holder(s) directly, unless additional rights are indicated by a Creative Commons license in the record and/or on the work itself. For more information, please contact digitalcommons@fairfield.edu. 


\section{Authors}

Diana Mager, Meredith Wallace Kazer, Jaclyn Conelius, Joyce M. Shea, Doris T. Lippman, Roben Torosyan, and Kathryn Nantz

This article is available at DigitalCommons@Fairfield: https://digitalcommons.fairfield.edu/nursing-facultypubs/58 


\section{Research Article}

Diana R. Mager*, Meredith W. Kazer, Jaclyn Conelius, Joyce Shea, Doris T. Lippman, Roben Torosyan and Kathryn Nantz

\section{Development, Implementation and Evaluation of a Peer Review of Teaching (PRoT) Initiative in Nursing Education}

\begin{abstract}
For many years, an area of research in higher education has been emerging around the development and implementation of fair and effective peer evaluation programs. Recently, a new body of knowledge has developed regarding the development and implementation of fair and effective peer evaluation programs resulting in formative and summative evaluations. The purpose of this article is to describe the development, implementation, and evaluation of a peer review of teaching (PRoT) program for nursing faculty, initiated at one small comprehensive university in the northeastern United States. Pairs of nursing faculty evaluated each other's teaching, syllabi, and course materials after collaborating in a pre-evaluation conference to discuss goals of the classroom visit. Qualitative data gathered in post project focus groups revealed that faculty found their modified PRoT process to be a mutually beneficial experience that was more useful, flexible and collegial, and less stressful than their previous evaluation process.
\end{abstract}

Keywords: peer review of teaching, peer evaluation, nursing education, teaching

DOI 10.1515/ijnes-2013-0019

For many years, research in higher education has explored the development and implementation of fair and effective peer evaluation programs. Typically, the aim is to produce data for both formative review - defined as the

*Corresponding author: Diana R. Mager, School of Nursing, Fairfield University, North Benson Rd, Fairfield, CT 06824, USA, E-mail: dmager@fairfield.edu

Meredith W. Kazer: E-mail: MKazer@Fairfield.edu, Jaclyn Conelius: E-mail: jconelius@fairfield.edu, Joyce Shea: E-mail: jshea@fairfield. edu, Doris T. Lippman: E-mail: lippman@fairfield.edu, School of Nursing, Fairfield University, Fairfield, CT, USA

Roben Torosyan, Bridgewater University, Bridgewater, MA, USA, E-mail: roben.torosyan@bridgew.edu

Kathryn Nantz, Department of Economics, Fairfield University, Fairfield, CT, USA, E-mail: nantz@fairfield.edu provision of feedback in order to facilitate professional growth (Hulsmeyer \& Bowling, 1986) - and summative evaluations -defined as the provision of evidence to be used in decisions about promotion, annual salary increases, and tenure. As institutions increasingly focus on assessment of teaching and learning, Peer Review of Teaching (PRoT) programs are being redesigned for both purposes, as well as to improve student learning and to compare programs across institutions (Chism, 2007). When trust and reciprocal reflection are integrated, peer review can benefit both the reviewer and the instructor being reviewed (Boye \& Meixner, 2010) such as by starting with "Observing you made me think about things I should do differently in my own teaching."

While the nursing literature is replete with discussions of the advantages of, and barriers to processes for reviewing teaching, and the development of valid and reliable tools, there have been no reports of a school developing and testing its own process as part of a larger institutionwide initiative. The purpose of this article, then, is to describe the development, as well as implementation and evaluation, of a new PRoT program for nursing faculty, initiated at a small comprehensive university in the United States. The article provides, first, a model for other universities wanting to design PRoT programs that align with best evaluative practices, and second, the results of a focus group designed to assess this new model's outcomes.

\section{Motivation and literature review}

Before our School of Nursing (SON) chose to pursue this project, our existing system of classroom evaluation was as dated as many depicted in the literature, where the focus is solely on senior faculty classroom reviews for the purpose of promotion and tenure (Keig, 2000). These dated systems have, at times, placed junior faculty in situations in which senior colleagues visited a classroom, wrote an evaluation based on a single observation, and 
then left a letter in the evaluated faculty mailbox to be interpreted independently. This process was wrought with anxiety over the impending evaluative visit and in some cases distress over the written remarks, typically left without much if any explanation. The strategy also left the junior faculty feeling that if an evaluation dismayed them, they could do little about it for fear of losing support of the senior colleague at the time of promotion and/or tenure. Before a university-wide PRoT initiative, described below, began, faculty may have also resisted classroom visits when they feared biased reviews (Brannigan \& Burson, 1983) or when they felt that they had little involvement in the process (Brown \& Ward-Griffin, 1994). Our pilot project attempted to create a less stressful and more productive climate around assessment and evaluation of teaching. Our question was: Could we design a system of peer review of teaching that would (1) provide formative feedback for improvement, (2) provide summative feedback for personnel decisions, (3) potentially help to generate improved student learning outcomes, and (4) be conducted without damaging collegiality and instead building trust and collaboration.

Many faculty view the process of being evaluated as arduous but necessary. However, research has shown ways to humanize the work for mutual reflection and transformation. Carter (2008) suggests the reviewer be open to alternative teaching methods, conduct a pre-visit interview, watch students during class for clues about learning, and focus on helping faculty members make improvements and follow best practices during post-visit conversations. Best practices suggest that the traditional classroom visit be supplemented by other forms of review, including assessment of syllabi, curriculum, and course materials as well as interpretation of student opinions of teaching (Chism, 2007). This richer evaluation process requires educating reviewers in three main areas: (1) judging teaching plans, teaching philosophies, or other teaching materials; (2) giving and receiving observation feedback and writing observation narratives; and (3) interpreting student ratings. When triangulation of data is used for analysis, productive conversations between faculty members can often result, in turn improving student learning.

Even with a richer array of teaching artifacts, it is very difficult to rigidly separate formative from summative evaluations. An evaluator plays a critically important role in creating an atmosphere of trust and collegiality. In a seminal work on reflective faculty evaluation, Centra (1993) argued that what matters most is how feedback is used "not intended use but actual use" (p. 5). That is, if feedback about positive strengths given to encourage improvement then gets included as evidence for an annual review decision, the feedback must be thought of as summative and not formative. Furthermore, those who give formative feedback should not later be asked to give summative evaluation, because "teachers will not be as open to discussing weaknesses or seeking advice from people who will also judge them" (Centra, 1993, p. 5). In response to somewhat rigid and unrealistic efforts to distinguish between formative and summative evaluations, Bernstein, Johnson and Smith (2000) recommended "alternating periods" when development and evaluation occur, keeping faculty "shielded from scrutiny for periods of a few years," before tenure or before promotion to full professor. Through this process, the faculty member is encouraged to "generate substantial improvement in teaching that can be brought forward during periodic times of accountability" (p. 83). Research shows that feedback will result more often in visible improvements to teaching practice when the recipient has some control over the evaluation process (Baehr, 2003), and when observations specify actual behaviors (actions that instructor or students took). Likewise, when negative information "is self-referenced (that is, negative information ... compares one's performance to other measures of one's ability)" rather than "norm-referenced (that is, negative information ... compares one's performance to others' performance)," then rather than lose self-esteem or motivation, instructors are more likely to attribute their performance to their effort and their own self-expectations (Brinko, 1993, p. 583).

Peer review of teaching is often tied to mentoring. Traditionally, however, people assume a top-down, oneon-one relationship between experienced or higherranked faculty and new or lower-ranked faculty. The assumption is that the senior faculty member is providing instruction to the junior colleague. Recent models, however, emphasize reciprocal reflection by mentors and mentees (Boye \& Meixner, 2010), teaming early-career faculty with "multiple mentors" (de Janasz \& Sullivan, 2004) or using "constellations" or "networks" of mentors to address different competencies (Sorcinelli \& Yun, 2007). The reciprocal nature of these relationships creates greater collegiality in the process and allows not just junior but senior faculty to improve their own practice through the process of reviewing and mentoring.

\section{Development of peer evaluation in nursing}

While the literature on peer evaluation in nursing reflects many of the same issues described above, there are also 
unique aspects of the discipline that both complicate and complement the integration of PRoT processes. Page and Loeper (1978) made the first reference to Peer Review (PR) for nurse educators, while Dennis, Woodtli, Hatcher, and Hilton (1983) were first to discuss the development of a PR process and deTornyay (1983) introduced the role of peer evaluation in reviewing clinical teaching, scholarly activities, and community involvement in addition to classroom teaching. Early criticisms of the PR process addressed faculty members' fears of biased and unjust reviews (Brannigan \& Burson, 1983) and possible infringement on academic freedom (Dennis et al., 1983). To reduce anxiety of faculty being evaluated and to increase the representativeness of the data, Braskamp, Brandenburg, and Ory (1984) suggested increasing the number of peer evaluators involved in the process. Questions about the validity of the process, especially when promotion and tenure decisions are involved, have generated a variety of suggestions for specific areas to review and templates to use (Andrusyszyn, 1990; Berk, Naumann, \& Appling, 2004; Costello, Pateman, Pusey, \& Longshaw, 2001). All of this work has helped to increase the professionalism of classroom teaching in nursing and has led to improvements in the ways that nursing faculty approach the evaluation process.

Several researchers argue that faculty in a SON need to be directly involved in the creation and revision of a PR system and should be clearly informed about exactly what aspects of teaching will be evaluated, as well as how, when, and why (Brown \& Ward-Griffin, 1994; Sullivan, 1985). In the complex process of faculty evaluation, it is considered most important to "obtain a comprehensive, representative picture of the educator's performance from relevant sources" (Andrusyszyn, 1990, p. 413). Despite an early reliance solely on student evaluations, Brown and Ward-Griffin stated that "no one method of evaluation can provide a complete picture of teaching effectiveness" ( $p$. 301). To inform summative reviews by administrators and to further establish the evidence base for effective teaching in nursing, Appling, Naumann, and Berk (2001) and Polifroni (2008) recommended using peer evaluations along with student evaluations and faculty-created teaching portfolios. Ward-Griffin and Brown (1992) concluded that faculty evaluation and faculty development were inextricably linked.

Reports of the use of PR in the evaluation of clinical teaching (Ludwick, Dieckman, Herdtner, Dugan, \& Roche, 1998; Secomb, 2008) and teaching in web-based courses (Cobb, Billings, Mays, \& Canty-Mitchell, 2001) have addressed some of the unique needs in nursing. For example, Berk and colleagues (2004) shared information on the psychometric properties of two peer observation scales that they developed for use at the Johns Hopkins University SON; one tool is designed for the traditional classroom setting and the other is an appraisal form for clinical faculty.

The remainder of this paper describes a unique process begun at one SON that required teams of faculty members to be evaluated themselves and also to evaluate colleagues. The PRoT process that emerged was designed to bridge the gap between formative and summative evaluations by implementing an approach of partnership and co-mentoring to this important work.

\section{Methods}

Because this pilot project was a form of program evaluation, it was deemed exempt from Internal Review Board (IRB) review. Our initiative began when five volunteer nursing faculty members, along with faculty teams from other schools and departments at our university, attended a two-day workshop on PRoT offered by the university's Center for Academic Excellence (CAE). This workshop, funded by the Davis Educational Foundation, was purposefully designed to respond to faculty demand from across disciplines and schools for help developing best practices and successful strategies. The goal was to design PRoT programs that shared common guiding principles across campus, but that also accommodated disciplinary idiosyncrasies reflected in teaching practices. For example, nursing programs have a wide variety of settings in which instruction occurs, including classrooms, labs, hospitals, and clinics, to name a few. A department like performing arts, on the other hand, has a performative element that is quite different from the clinical expertise that nurses must master. There are similarities here - both departments involve students in significant experiential learning opportunities which faculty must design and oversee - but each has its unique elements that require attention.

During the first workshop day, SON faculty engaged in lengthy discussions about the role of PRoT in the School and developed a statement that reflected their values related to PRoT (Table 1). During the second workshop day, the team developed an action plan for implementation and evaluation of the new PRoT system through the 2011-2012 academic year (Table 2). These materials were revised and vetted by the team during the fall semester and were ready for review by the entire SON faculty in January 2012. 
Table 1 School of Nursing statement of peer review of teaching (PRoT)

1. The School of Nursing may benefit from establishing a system of peer review of teaching (PRoT) beyond classroom observation and student evaluation.

2. Potential benefits of a PROT system may include cross course sharing, content suggestions, enhanced teaching and learning practices, improved student achievement of program outcomes faculty satisfaction and success, work efficiency, and University effectiveness.

3. The PRoT will be developed with input of School of Nursing faculty. The PRoT process will be articulated and shared with faculty through monthly faculty organization and curriculum committee meetings and through the School of Nursing mentoring process.

4. The PRoT is a formative process. Faculty are encouraged to participate in the PRoT process as part of a comprehensive teaching portfolio that includes the documentation of course improvements in response to PRoT and student evaluations. This teaching portfolio may be utilized as a summative evaluation for the purpose of merit evaluations and promotion and tenure review.

5. PRoT includes, but is not limited to, classroom observation, review of syllabus and course design, student evaluations, teaching selfassessment, and student performance.

6. The School of Nursing faculty are encouraged to participate in the PRoT process on an annual basis and as deemed appropriate (e.g. new course, new faculty) and may be considered for the purposes of Merit evaluation.

7. Faculty who have not yet received tenure are expected to utilize the PRoT process at least once each semester and are encouraged to involve the maximum number of tenured faculty in this process. Consideration should also be given for utilization of the PRoT process for clinical and adjunct faculty.

8. Peer reviewers may be chosen based on their expertise in content knowledge, teaching methods, student communication, assessment or development of course materials such as handouts and readings. Peer reviewers do not necessarily need to be senior in rank to the faculty member being reviewed.

9. Peer evaluations should be initiated by the faculty interested in being reviewed, in conjunction with their faculty mentor, if applicable. This process places ownership for evaluation on the faculty member in order to ensure that all areas of teaching are evaluated as needed.

Table 2 PRoT goals and action plan

\begin{tabular}{|c|c|c|c|}
\hline Goal & Action plan & By when? & By whom? \\
\hline $\begin{array}{l}\text { The School of Nursing will adopt } \\
\text { PRoT Statement }\end{array}$ & $\begin{array}{l}\text { Introduce PRoT in September Meeting } \\
\text { followed by further review and } \\
\text { acceptance in October Meeting }\end{array}$ & $\begin{array}{l}\text { December 9, } 2011 \\
\text { Faculty meeting }\end{array}$ & $\begin{array}{l}\text { SON PRoT Team } \\
\text { DM to tell AK to add to } \\
\text { agenda }\end{array}$ \\
\hline $\begin{array}{l}\text { Enhance understanding of PRoT } \\
\text { programs in other Schools of } \\
\text { Nursing }\end{array}$ & $\begin{array}{l}\text { Conduct review of PRoT programs in other } \\
\text { Schools of Nursing }\end{array}$ & December 2011 & $\begin{array}{l}\text { JC and JS to send email } \\
\text { to schools }\end{array}$ \\
\hline $\begin{array}{l}\text { Develop evaluation documents for } \\
\text { PRoT within SON }\end{array}$ & $\begin{array}{l}\text { Work as team to revise and adapt } \\
\text { resources to meet needs of SON }\end{array}$ & December 2011 & DM and MK \\
\hline $\begin{array}{l}\text { Conduct educational program for } \\
\text { SON faculty on PROT }\end{array}$ & $\begin{array}{l}\text { In conjunction with CAE develop and } \\
\text { implement } 2-3 \text { hour educational program } \\
\text { on PRoT }\end{array}$ & $\begin{array}{l}\text { January 27, } 2012 \\
11 \text { AM - } 1 \text { PM (with lunch) }\end{array}$ & $\begin{array}{l}\text { SON PRoT Team and } \\
\text { CAE }\end{array}$ \\
\hline Pilot PRoT program with SON faculty & $\begin{array}{l}\text { Select minimum of } 5 \text { dyads to utilize PRoT } \\
\text { during spring semester }\end{array}$ & February - April 2012 & $\begin{array}{l}\text { SON Faculty and PRoT } \\
\text { Team }\end{array}$ \\
\hline $\begin{array}{l}\text { Evaluate and disseminate SON PRoT } \\
\text { program }\end{array}$ & $\begin{array}{l}\text { Conduct focus group with SON PRoT dyad } \\
\text { participants } \\
\text { Report on results of pilot at FDEC meeting } \\
\text { and through scholarly publication }\end{array}$ & May 2012 & SON PRoT Team \\
\hline
\end{tabular}

One of our first tasks was to determine what other SONs were doing in relation to PRoT. To begin this process, two members of the committee contacted academic nursing colleagues in our Jesuit network via telephone and email. Committee members inquired as to the system of PRoT in colleagues' respective schools and asked them to share any materials that might be helpful. While some schools were using no system of PRoT, others shared resources that were validated in the literature and helpful in furthering the action plan.
The team presented a workshop for the full SON faculty in January 2012 to share ideas and encourage buy-in from all stakeholders, including both junior and senior faculty and SON administrators, and to launch a pilot program for the team's work. Participants readily agreed that conversation between colleagues before a classroom visit would be particularly useful when the upcoming topic or course was unfamiliar to the reviewer. Participants also recognized the value of learning from colleagues who have particular clinical or technological 
expertise. Time constraints, which could limit implementation of the system, were of concern to faculty. The use of phone or video chats for pre-observation or debriefing and the possibility of lecture capture and "podcasting" were discussed as possible ways to save time.

The workshop concluded with a presentation of a newly developed PRoT rubric that the team adapted from the work of Chism (2007). The purpose of the rubric is to provide a menu of options for evaluating both teaching experiences and artifacts. Prior to the classroom visit, faculty partners meet and complete page one of the rubric. They discuss the goals the upcoming observation, and logistics such as where and when the class meets. The remaining pages of the rubric consist of 5-point Likert scales used to rate various dimensions of classroom teaching including: organization, clarity, teaching strategies, presentation skills, content knowledge, and rapport with students (Chism, 2007). Each section is further broken down to include more specific topics, such as use of technology or humor in the classroom, and ends with space for reviewer comments. Finally, the rubric includes options to rate the syllabus, tests, and/or clinical instruction. The purpose of the rubric is to provide PRoT partners with a range of possible items to consider when reviewing a colleague's teaching without expecting anyone to achieve all or even most items. At any time, some of these might be more or less important, depending on contextual factors such as the particular course, assignments or delivery platform. Given this range of options, each faculty member chooses the assessment components that will be under consideration, providing an element of control for individual faculty members and also flexibility in the process itself. As described in the literature review, control and flexibility are centrally important to faculty investment and trust in the entire process.

After reviewing the new rubric, faculty at the workshop organically formed six dyads (made up of faculty from all ranks) and agreed to work together for the remainder of the spring semester to pilot the new PRoT system. At semester's end, a focus group was conducted with members of the dyads to evaluate the program (Table 3 ).

\section{Findings}

Seven of the twelve participating faculty members (representing five of the six dyads) attended the post-implementation focus group, which was facilitated by a staff member from the CAE. Comments confirmed the importance of some of the best practices implemented by the SON PRoT team and provided support for the usefulness
Table 3 Focus group evaluation questions

1) How would you describe your experience as a member of a dyad in the new SON PRoT process?

a. What worked well?

b. What were the challenges?

2) Regarding the new PRoT forms/documents:

a. How useful did you find them to be?

b. What suggestions for changes do you have?

3) How did your experience in the dyad compare with your past experiences with PRoT?

4) What suggestions do you have for moving the PRoT process forward in the SON?

of new tools. In response to the first question, "How would you describe your experience as a member of a dyad in the new SON PRoT process?" many focus group participants described it as an "excellent experience." One participant felt that the pre-observation meeting and the PRoT rubric "gave a better structure to our [PRoT] vision/process" while another stated that the new process "was very helpful to guide a holistic evaluation of the course."

Several participants described how the new process led to increased opportunities for collaboration and creativity: "I enjoyed talking to the other professors about what went well with my lecture and the changes recommended for the next semester" and "[I enjoyed] pairing up with a faculty member who had similar interests... getting a chance to plan our work together." The new process also seemed to increase the participants' overall comfort with PRoT, in part because of the flexibility built into the process "[I liked] the way it just happened. Nothing was mandated. You could choose to do what you wanted" and in part because the process was built on trust among colleagues: "I loved the fact that we already knew each other, had a sense of each other's strengths and areas for growth - most of us working together many years. A lot of the trust was already there." It became clear that the transparency created by the new system encouraged trust (as opposed to the old system that seemed to promote fear and resentment), setting the stage for what participants described as a new mutually beneficial and reciprocal process:

[I liked] the focus on reciprocal learning and relationships: less evaluation and more of a focus on how I can be a better teacher. Going into this as a dyad made it a much more collegial process. Less hierarchical in intention.

As a senior [faculty member] partnered with junior faculty, I was much more conscious of what I was doing right or wrong, thinking about it differently for myself - so it helped me selfevaluate my own teaching better having my junior partner. 
Finally, several participants noted that the process led to unintended/unexpected benefits:

The pre-assessment really helped. But when my partner and I met for the post-assessment, I asked "Don't you get bored lecturing so much?" She said "Yes. What do you do about that?" I shared that I break them into groups and do activities. This was an unintended benefit because my partner didn't ask for this feedback but it helped her teaching.

The single greatest challenge, verbalized by some participants, how much time the process demanded: "It took time to really review the texts and syllabus well" and "[It was challenging to] find enough time to plan everything; some of our goal setting was done on the fly." Other participants found that the new PRoT process required approximately the same time as the old process: "Time is always a challenge but this process did not take any longer than the old process" and "Surprising, however, that this didn't take more time for several of us; [we] just completed the rubrics while in class." An important benefit to the new process, however, on which further research should be conducted, was that much of this work was already required of the SON by outside accrediting bodies. Thus, when one makes review of teaching part of existing practices, one can achieve multiple purposes, and therefore save precious time.

The second focus group question asked participants to specifically comment on the new rubrics developed for PR. Overall, participants found them to be an improvement over the previous simple class observation rubric: "[The] new rubric allows all of our points to be included and then we get to choose what exactly we want peer evaluation on; very helpful obtaining my dyad partners' feedback on my teaching"; "Very useful for class, also nice first page to go over and to evaluate what exactly you want to focus on"; "[The rubric is] very useful for organizing ourselves. [It] covered areas we may not have thought about"; and "The rubrics gave a lot of criteria, right there, to know what to look for." However, faculty suggested that the rubric could be improved: "Make it clear that not every component must be filled out [each time] and faculty Probably need to think about ways to differentiate rubrics for formative versus summative evaluation." These comments reflect the common cause created by this open and inviting process and highlight the evolutionary nature of the work as it is practiced and continually improved by all participants.

The third question asked people to compare participation in the dyad as part of the revised PRoT process with previous experiences of peer evaluation. Focus group participants were uniformly positive about the new procedure, finding it to be "a much richer experience", and "much less stressful, more fun and contributed to relationship building." In contrast to the old process, one participant stated that the new PRoT process "seemed more useful and more user friendly... Rather than meeting a requirement for promotion, I was improving my teaching." These comments helped to reinforce the notion that not only collegiality and collaboration but authentic motivations and reasons to engage are critical to a productive review process.

The final focus group question asked participants to provide suggestions for moving the PRoT process forward in the SON. Most of the participants recognized the need to continue to review and revise the process, with ongoing discussion at faculty meetings and efforts to update the rubrics on a regular basis. One participant felt a further obligation to "share the rubrics and processes across campus." Several participants emphasized the importance of keeping options open for individual faculty members, especially when the process is for summative rather than formative purposes: "Make it optional for the person seeking summative evaluation to make the choice of who gets to do that" and "Write in that people should find their own formative partners, and summative judges." The notion of choice arose again in comments supportive of efforts to "empower [the faculty] to find the right person for themselves, not just in SON but from other schools [within the University] too."

Participants were sensitive to the potential burden imposed by the new PRoT process. One participant suggested that the new process needed to "fit with our accreditation processes, to show continuous program improvement, one of the specific standards. Faculty evaluation is a part of this. Tie it back to what the impact is on students." In addition, participants did not wish to lose the benefits of a parallel mentoring process that had been unfolding at the SON, identifying the need to "Figure out how this PRoT process fits with mentoring we have for promotion and tenure. It's separate but can assist."

Overall, participants did not want to go back to the old "just come in and write the letter" approach to PRoT. One participant suggested the need to "maintain the collegial culture in SON. We mentor each other here. We take care of our own. We want to maintain the trust we have for each other. Just make it more specific."

\section{Discussion}

Standards for education and teaching practice in nursing have improved greatly over the past several decades. The 
recent Institute of Medicine (IOM, 2010) report on the Future of Nursing recommends that "Nurses should achieve higher levels of education and training through an improved education system that promotes seamless academic progression.” Improved nursing education systems that foster the success of faculty teaching, scholarship, and service will provide the best environments for student learning. Thus, the time is ideal to implement systems of nursing faculty evaluation that promote faculty success in a climate of caring and concern for the individual welfare and success of each of faculty member. Students will be the obvious beneficiaries of this productive atmosphere, at any institution.

Worthy of note is the choice to implement an evidence-based process and to follow the model of Carter (2008). The revised process at our SON allowed faculty to choose their evaluator based on a broader set of criteria than simply senior status. In fact, faculty members were encouraged to choose a partner whose teaching they admired or who possessed a clinical or teaching expertise that they were interested in learning about in greater detail. The benefits of this partnership were reciprocal, much as Boye and Meixner (2010) describe. The revised system was also expanded to include a pre-evaluation meeting, a minimum of one classroom observation (although faculty chose to visit more often and one dyad chose to co-teach a session), and a post visit debriefing. The pre-evaluation meeting was very helpful in decreasing the faculty anxiety about the actual classroom visit. The debriefing fostered a full-explanation of the findings as well as additional discussion and suggestions for improvement. The new rubrics that were adapted from the work of Chism (2007) provided guidelines for the pre- and debriefing visits and gave opportunities to evaluate classroom teaching on many levels as well as to evaluate the tests, syllabi, or clinical teaching of faculty. Developing these templates also improved the validity of the PR process (Andrusyszyn, 1990; Berk et al., 2004).

Overall, changes to the PRoT process were seen as very positive. From the beginning, individual nursing faculty spearheaded the revision process and sought buy-in from all SON faculty members, as recommended by Brown and Ward-Griffin (1994). Faculty comments indicated that they enjoyed participating and they provided rich feedback about the experience, including some unintended consequences. Important suggestions for revising the rubrics were provided and will be considered as the process moves forward. Suggestions were also made as to how this process may fit in with an overall enhanced mentoring program within the University and
SON. That important and parallel strategic initiative will also be essential to the continued success of the peer evaluation program.

\section{Conclusions}

Nationally, PRoT programs have been criticized for lacking validity and reliability as well as for causing anxiety and disengagement of faculty. These realities constrain personal and professional growth and can lead to less than optimal learning environments for student nurses. However, effective PRoT is essential in SONs, to meet the needs for both formative and summative reviews, and to respond to demands of accreditation. The model presented here may serve as a guide to faculty programs and departments on other campus facing similar needs and challenges.

\section{References}

Andrusyszyn, M. A. (1990). Faculty evaluation: A closer look at peer evaluation. Nurse Education Today, 10, 410-414.

Appling, S. E., Naumann, P. L., \& Berk, R. A. (2001). Using a faculty evaluation triad to achieve evidence-based teaching. Nursing and Health Care Perspectives, 22, 247-251.

Baehr, M. (2003). Overview of assessment. In S. Beyerlein \& D. Apple (Eds.), Faculty guidebook: A comprehensive tool for improving faculty performance. Hampton Beach, NH: Pacific Crest.

Berk, R. A., Naumann, P., \& Appling, S. E. (2004). Beyond student ratings: Peer observation of classroom and clinical teaching. International Journal of Nursing Education Scholarship, 1, 1-26.

Bernstein, D. J., Johnson, J., \& Smith, K. (2000). An examination of the implementation of peer review of teaching. In Katherine E. Ryan (Ed.), Evaluating teaching in higher education: A vision for the future. New directions for teaching and learning (pp. 73-86). San Francisco, CA: Jossey-Bass.

Boye, A., \& Meixner, M. (2010). Growing a new generation: Promoting self-reflection through peer observation. In J. E. Miller \& J. E. Groccia (Eds.), To improve the academy: Resources for faculty, instructional, and organizational development (Vol. 29, pp. 18-31). San Francisco, CA: Jossey-Bass.

Brannigan, C. N. \& Burson, J. Z. (1983). Revamping the peer review process. Journal of Nursing Education, 22(7), 287-289.

Braskamp, L. A., Brandenburg, D. C., \& Ory, J. C. 1984. Evaluating teaching effectiveness: A practical guide. Beverly Hills, CA: Sage.

Brinko, K. (1993). The practice of giving feedback to improve teaching: What is effective? Journal of Higher Education, 64(5), 574-594.

Brown, B., \& Ward-Griffin, C. (1994). The use of peer evaluation in promoting nursing faculty teaching effectiveness: A review of the literature. Nurse Education Today, 14, 299-305. 
Carter, V. K. (2008). Five steps to becoming a better peer reviewer. College Teaching, 56(3), 85-88.

Centra, J. A. (1993). Reflective faculty evaluation: Enhancing teaching and determining faculty effectiveness (1st ed.). San Francisco, CA: Jossey-Bass.

Chism, N. V. N. (2007). Peer review of teaching: A sourcebook (2nd ed.). Bolton, MA: Anker.

Cobb, K. L., Billings, D. M., Mays, R. M., \& Canty-Mitchell, J. (2001). Peer review of teaching in web-based courses in nursing. Nurse Educator, 26, 274-279.

Costello, J., Pateman, B., Pusey, H., \& Longshaw, K. (2001). Peer review of classroom teaching: An interim report. Nurse Education Today, 21, 444-454.

de Janasz, S. C. \& Sullivan, S. E. (2004). Multiple mentoring in academe: Developing the professional network. Journal of Vocational Behavior, 64, 263-283.

Dennis, C. M., Woodtli, A. O., Hatcher, B. J., \& Hilton, A. M. (1983). Peer evaluation: A process of development. Journal of Nursing Education, 22(2), 93-95.

deTornyay, R. (1983). Why peer review? Journal of Nursing Education, 22(3), 143.

Hulsmeyer, B. S., \& Bowling, A. K. (1986). Evaluating colleagues' classroom teaching effectiveness. Nursing Educator, 11(5), 21.
Institute of Medicine. (2010). The future of nursing: Leading change, advancing health. Consensus Report of the Institute of Medicine of the National Academies. October 5, 2010.

Keig, L. (2000). Formative peer review of teaching: Attitudes of faculty at liberal arts colleges toward colleague assessment. Netherlands: Springer.

Ludwick, R., Dieckman, B. C., Herdtner, S., Dugan, M., \& Roche, M. (1998). Documenting the scholarship of clinical teaching through peer review. Nurse Educator, 23, 17-20.

Page, S. \& Loeper, J. (1978). Peer review of the nurse educator: The process and development of a format. Journal of Nursing Education, 17(9), 21-29.

Polifroni, E. C. (2008). Evaluating teaching strategies: A blended perspective. Journal of Nursing Education, 47, 95-97.

Secomb, J. (2008). A systematic review of peer teaching and learning in clinical education. Journal of Clinical Nursing, 17, 703-716.

Sorcinelli, M. D., \& Yun, J. (2007). From mentor to mentoring networks: Mentoring in the new academy. Change, 39, 58-61.

Sullivan, M. J. (1985). Faculty evaluation our shackle or parachute? Nursing and Health Care, 6(8), 447-448.

Ward-Griffin, C., \& Brown, B. (1992). Evaluation of teaching: A review of the literature. Journal of Advanced Nursing, 17(12), 1408-1414. 
Copyright of International Journal of Nursing Education Scholarship is the property of De Gruyter and its content may not be copied or emailed to multiple sites or posted to a listserv without the copyright holder's express written permission. However, users may print, download, or email articles for individual use. 